\title{
Sheffield

\section{Under-tapped potential: Practitioner research as a vehicle for widening participation}

GAZELEY, Louise, LOFTY, Fay, LONGMAN, Penny and SQUIRE, Ruth Available from Sheffield Hallam University Research Archive (SHURA) at: http://shura.shu.ac.uk/24540/

This document is the author deposited version. You are advised to consult the publisher's version if you wish to cite from it.

\section{Published version}

GAZELEY, Louise, LOFTY, Fay, LONGMAN, Penny and SQUIRE, Ruth (2018). Under-tapped potential: Practitioner research as a vehicle for widening participation. Journal of further and higher education.

Copyright and re-use policy

See http://shura.shu.ac.uk/information.html 


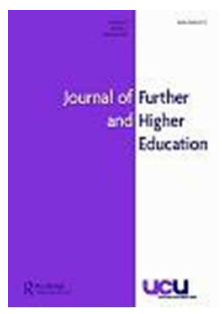

\section{Under-tapped potential: practitioner research as a vehicle for widening participation}

\begin{tabular}{|r|l|}
\hline Journal: & Journal of Further and Higher Education \\
\hline Manuscript ID & Draft \\
\hline Manuscript Type: & Original Paper \\
\hline Keywords: & widening participation, practitioner research, higher education \\
\hline \multicolumn{2}{l}{} \\
\hline
\end{tabular}

\section{SCHOLARONE}

Manuscripts 


\section{Under-tapped potential: practitioner research as a vehicle for widening participation}

\section{Introduction}

This paper makes an original contribution to on-going debates around the relationship between research, policy and practice, drawing on the first-hand experiences of three practitioner-researchers working to widen participation to university in England who had recently successfully completed a research-based MA. While this group of professionals is central to the success of this important international policy agenda, in England they are a diverse group ${ }^{1}$ and surprisingly lacking in access to bespoke professional development pathways in Higher Education (HE). They are also largely absent from the academic literature and in England, positioned within a dominant 'what works' agenda (Francis et al, 2017) in ways that tend to subordinate them to the data they collect. Approaches adopted under this agenda have been critiqued for a tendency towards analytical over-simplification (Gorard and Smith, 2006; Harrison and McCaig, 2015; Dockery, 2016; Lynch et al. 2015; Harrison and Richardson, 2017). Practitioner research affords an important complementary approach with high transformative potential as it is thoroughly grounded in the complexities encountered in routine practice while also inviting a critical reconfiguration of these (Carr, 2007). Zeichner (2003, p.46) further argues that the sharing of such stories helps to maximise their transformative potential.

The next section provides an overview of key debates surrounding the relationship between research, policy and practice with particular reference to the widening participation (WP) agenda. This is followed by a short section that further contextualises the discussion of the first hand-accounts provided by three practitioner-researchers following a bespoke WP strand of an MA in Education. This location reflects the lack of recognition of WP as an academic discipline and it also explains why much of the practitioner-research literature drawn on in the following section comes from other areas, particularly education. The paper concludes by drawing across the three accounts to highlight the under-tapped potential of what is an increasingly important professional group given their centrality to what is a key international policy agenda.

\section{Research and practice in the context of WP}

Hammersley (2008, p.238) argues that the increased emphasis on evidence-based policy making and practice in England has been designed to reduce research to a highly instrumental role that makes the public sector more accountable. This seems to be supported given current approaches to evidencing the impact of WP interventions and the

\footnotetext{
${ }^{1}$ Being spread across schools, colleges, universities and third sector organisations
} 
part played by the Office for Fair Access (OFFA) in both regulating and monitoring the sector. There is a strong emphasis on the quantification of indicators to evidence 'success ${ }^{2}$, with 'target groups" but also a nascent interest in fostering a research culture amongst practitioners ${ }^{4}$. A heavy emphasis on evaluation as a means of identifying 'what works' incorporates a broad trend at policy level to identify the Randomized Controlled Trial as 'the gold standard' (Hammersley, 2008; Francis et al., 2017). Notwithstanding, there are divergent understandings of evaluation as a means of informing both policy and practice and the place of stakeholders within such frameworks (Khakee, 2003). Carr (2007) writing about education research highlights the importance of first questioning the understandings that underpin both while also emphasising the need to recognise practice as both socially situated and historically formed. Rather than producing "knowledge 'on' or 'about' (Carr, 2007, p.276) suggests that the aim should be to develop:

The kind of self-knowledge that enables practitioners to identify the unquestioned assumptions and irrational beliefs sustaining their practice and, by so doing....reconstruct their educational practice in a rational and reflective way.

This focus is important because WP practitioners bring different educational and life experiences to this agenda and both understand and approach it in different ways (Wilkins and Burke, 2015). Hammersley (2008, p.3) argues that the polarization between different research paradigms that underpins these debates is unhelpful. Francis et al. (2017), reflecting on the lack of transfer between research, policy and practice in the case of 'ability' grouping in England also conclude that what matters is an informed understanding of what different research approaches can/cannot do rather than any dogmatic hierarchy.

Any discussion of the potential for practitioner-research to contribute to positive change within the WP agenda needs to take account of the critiques previously levelled against research in this area. Gorard and Smith (2006) following a review of WP research raised concerns about its quality, suggesting that not only were conclusions and findings often conflated, but that not enough detail was provided to demonstrate their justification. While this critique is even handed in being applied to research of different types, practitioner research is specifically dismissed on the grounds that it "typically does not involve interventions, controls or even any explicit analysis of patterns and trends" and therefore

\footnotetext{
${ }^{2}$ Generally conceptualised as spanning initial engagement in interventions at the pre-entry stage, subsequent recruitment, retention and culminating in progression to graduate-level employment ${ }^{3}$ A major focus being those characterised as socially disadvantaged but also including young people in the care system, specific ethnic groups and those with disabilities.

${ }^{4}$ The 'pracademic' knowledge exchange programme that has matched academic mentors with practitioners: https://www.offa.org.uk/egp/writing-publication-widening-participation-practitioners/
} 
provides "no way of assessing its propositions or generalising its results" (Gorard and Smith, 2006, p.590). While Gorard and Smith (2006) are right to show that misunderstandings of research approaches can lead to misleading and unwarranted claims around causality. Hardwick and Worsley (2011, p.137) are also clear that practitioner-research deals so closely with the particularities of the context in which it is conducted that it sheds light only on what is transferable to similar settings. Such approaches would also seem to address the concern raised by Kettley (2007) that WP research has tended to look at different aspects in isolation rather than approaching them holistically. This tendency to atomisation is inherent in current approaches to evaluation in part because it relies on linking indicators of 'disadvantage' that are difficult to operationalise (Gorard, 2012; Harrison and McCaig, 2015; Dockery, 2016; Harrison and Richardson, 2017) to specific interventions in ways that underattend to the complexity of these intersections over time. It also risks reducing WP practitioners to data technicians rather than developing their capacity to be(come) agents of change (Gewirtz et al. 2009).

The contribution made by practitioner-research has been a continuing subject of debate across professional domains (Shaw 2005; Hammersley, 2008; Harridge et al, 2014). As already noted the literature on WP practitioners is scant, the paper by Wilkins and Burke (2015) being a notable exception and they therefore do not feature in these debates. Hardwick and Worsley (2011, p.136) argue that in the case of Social Work a lack of recognition of the value of practitioner-research is compounded by a lack of access to "highquality research training opportunities and supervisory support to facilitate a rigorous analysis." This situation is clearly worse for WP practitioners given their lack of access to a bespoke pathway in HE. Whitchurch and Gordon, (2010) reflecting on the growth of professional service staff in HE - the place where many but by no means all WP practitioners in England are located - also highlights a lack of status and recognition when compared with academic staff and more limited opportunities for Continuing Professional Development.

The research literature identifies a number of benefits as arising out of practitioner-research, including some that point to the potential to deliver immediate improvements in practice (what under other agendas might be called 'impact'). This potential for positive change is embedded in the process (Carr, 2007) and can be transformative of both the individual and their professional setting (Shaw, 2005; Gewirtz et al. 2009; Vetter, 2012; Harridge et al, 2014). In adopting a bottom up rather than top down approach the practitioner-researcher has more agency (Zeichner, 2003; Gewirtz et al., 2009; Killingsworth-Roberts et al 2010; Vetter, 2012). In fostering a capacity for critical reflection such approaches provide 
new/deeper insights into 'real world' problems (Killingsworth-Roberts et al, 2010; Vetter, 2012; Harridge et al, 2014) while also allowing access to marginalised/missing/alternative voices and perspectives (Harridge et al, 2014). Such approaches create opportunities to (better) integrate theory with practice (Vetter et al.2012), something that may never be required if simply inputting evaluation data. In "generating practitioner research capacity" (Shaw, 2005, p.1231) it also reduces the risk of under-tapped potential.

\section{Contextualising the practitioner-researcher accounts}

Shaw (2005 p.1232) characterises practitioner-research as "small-scale, local, grounded, and carried out by professionals who directly deliver those self-same services." The research conducted by the three practitioner-researchers discussed below exhibited all of these characteristics but was also conducted under the auspices of a research-based MA in Education programme with a bespoke WP strand developed to address an identified gap in provision. This provided access to a designated tutor with research expertise in WP plus a network of peer practitioner-researchers. It followed a staged process that comprised the following elements: critical reflection on a self-identified aspect of practice; an extended literature review; opportunities to develop knowledge and understanding of research; opportunities to conduct small-scale research culminating in a dissertation.

According to Gorard and Smith (2006 p.592) researchers have an "ethical responsibility to be appropriately sceptical" and the following discussion identifies this as the quality initially motivating the three practitioner-researchers to engage in study at Masters level. Gorard and Smith (2006 p.592) also identify two standards for evidence - Is what is presented plausible? and Does it change anything? - and again these accounts point to there being no inherent incompatibility with practitioner research. Hardwick and Worsley (2011) suggest that practitioner-research, by virtue of its situated nature, is particularly likely to identify areas of contradiction, including things missing from other research and policy agendas. The virtue of this closeness can be seen in the very different foci selected by the three practitionerresearchers and the range of changes that they gave rise to. Hammersley (2005) reflects that research and practice are rather different and that research might open up more complexity than practitioners can readily manage. These accounts suggest, however, that some practitioners are already well aware of these complexities and that their own research provides an opportunity to further illuminate them in ways that can inform individual and local practices but also wider debates.

\section{Discussion}

\section{Ruth: Theorising confidence}


The research conducted as part of the MA entailed a staged exploration of the concept of 'confidence' - a term used with increasing frequency in WP policy discourse ${ }^{5}$ and by participants, colleagues and teachers as a key objective and outcome of WP activity. Despite widespread use, I found no consistent definition of 'confidence' in the literature and no model of how it could support HE progression. Many constructions of confidence assumed a deficit in WP learners, with limited evidence for this. Despite no consistency in meaning or clear evidence base, I found that confidence is indicated as a goal of WP interventions (Cabinet Office, 2012), as a barrier to HE (Dent et al., 2012) and cited as a key outcome of interventions such as the Aimhigher programme (Church \& Kerrigan, 2011). Crucially, no definition of confidence addressed the thoughts and feelings of the young people and adults engaged in WP interventions. Interpretations of the value of confidence were rarely in their words and it was assumed that confidence would translate into behaviours uniformly across all groups despite indications that understandings and expressions of confidence are situated in, and may result from, different social and cultural contexts (Strand, 2007). Harris, in his role as Director of Fair Access, wrote about a lack of 'social confidence' inhibiting students from applying to particular institutions but offered no evidence of this being a root cause beyond absence of applications (Harris, 2010, p56). The literature appeared to be speaking in different languages and to different audiences. Practitioner literature lacked some of the context and discussion of reflexivity of research papers, making it sometimes confusing to understand. However, research papers were difficult to relate to my experience of working in WP and commentaries on policy changes did not reflect the impacts of these on practice. This research therefore presented an opportunity to gain an understanding of confidence that went beyond the simplistic and inconsistent definitions I encountered.

The dissertation research focused on the experiences of young people participating in a fiveday, non-residential university summer school. I took a multi methods approach, combining sequential focus groups with interviews and observations to explore participant and staff ideas around confidence and how this interacted with their experiences during the week. In total, six participants $(3 \mathrm{M}, 3 \mathrm{~F})$ aged $17 \& 18$, two student ambassadors $(1 \mathrm{M}, 1 \mathrm{~F})$ and one $\mathrm{PhD}$ student tutor $(\mathrm{F})$ participated in the focus groups and/or interviews, which took place before, during and after the summer school. I also observed four 'social' and 'academic' sessions during the five days. I was particularly aware of being careful to restrict the intrusion of the research into participants' experiences of the summer school and of the danger of making assumptions about participants' responses or observed behaviours.

\footnotetext{
${ }^{5}$ For example it appears in the National Strategy for Access and Student Success in Higher Education (BIS, 2014) 12 times
} 
However, I felt that my position presented opportunities not available to others, particularly in the level of access to participants and my ability to understand aspects of their experiences through shared language and environment.

I found tremendous value, both in the act of undertaking research and in the findings of the research itself, for my professional practice. Amongst the participants and staff I interviewed I found a complex variety of understandings of confidence - as both a feeling and a behaviour which shaped their responses to the activities within the summer school. For example, one participant spoke about confidence prior to the summer school as "being able to stand up in front of a crowd and voice your opinion" and focused throughout on the summer school's role in building her confidence to deliver a presentation in a supportive environment alongside her peers. However, another participant felt that confidence was about "belief in yourself that allows you to express your thoughts and feelings" and did not feel that the experience affected his confidence but that the social environment, with fellow students appearing nervous to talk in seminars, restricted his ability to express it. I also uncovered aspects that shook the confidence of some participants - something I was aware of but never truly forced to confront in my everyday practice:

I think for us it's been quite good but for other people it's been really hard so they might not be as sociable ... they kind of feel isolated and I think some people who are like that, they're not showing up now. (Focus group 2)

This variation in participant interpretation of experiences was largely absent from the literature I had explored but was important as a practitioner for understanding where differentiation may be needed, both when delivering activities and when evaluating them.

The participant who followed most closely the model of the students presented within the literature felt that he lacked confidence but emerged from the summer school with a new resolve to pursue a highly selective course and with a feeling that he had previously undervalued his academic abilities. Although he saw the summer school as a positive experience, he also identified that his academic confidence went down during the week and he expressed anxiety before and during the summer school about his ability to cope academically. He ascribed his increased confidence to the successful completion of many challenges, including the summer school, a change in his interpretation of his experiences and high-levels of peer support, including in relation to his dyslexia. This highlighted the complexity of the links between trajectories and specific interventions. Recognition of the importance of participants' wider contexts prompted conversations with colleagues about the 
framing of summer school experiences and led to more detailed information being provided to students but also to staff training around disability support at universities.

Importantly, neither participants nor staff identified a deficit of confidence that was specific to WP learners. Though participants recognised that they sometimes lacked certainty in their actions, they felt certain that their confidence would increase over time and with exposure to different environments. All appeared to take a proactive approach to developing their confidence and although they valued the experiences offered by the summer school, saw themselves as active partners throughout:

We could have just refused to do the presentation and we wouldn't have had that confidence boost...I think it does really rely on participation and the student's willingness to put themselves out of their comfort zone. (Final Interview)

This emphasis contrasts with some of the literature and served as an important reminder of the importance of considering participants as more than passive recipients of an experience.

The necessary practice of questioning assumptions (mine and others) as a researcher led me to a better understanding of the assumptions evident in WP activity. I had previously understood summer schools to be an 'effective' WP intervention (OFFA, 2013). Whilst my research did indicate that the summer school experience had value for participants, in specifically questioning the use of confidence in WP discourse I brought awareness, not only to myself but to colleagues, of the power of language in shaping our assumptions of those we are seeking to support. Although such debates are not new I believe that, as a practitioner, I was able to make these considerations more relevant and accessible to colleagues who may not have engaged with research papers or academic discussions. As a consequence, some of the language that we used to communicate about our work, both internally and externally has changed. Undertaking research within the context of my own professional practice was empowering for myself and for my colleagues who could see in our discussions the value of their professional insight. It fostered an increased interest in WP research within the setting, leading to the introduction of a 'journal club'. In a sector where academic research has taken many years to filter through, encouraging practitioners to research their own practice develops common ground and understanding between researchers and practitioners.

\section{Fay: Accessing 'hard to reach' perspectives}

Despite a long history in WP, England still faces a social divide in access to HE with young people from more advantaged backgrounds being six times more likely to study at university 
than their less advantaged peers (UCAS End of Cycle Report 2016). Schools and young people are targeted for interventions based on a range of related criteria: where the family lives, parental history of $\mathrm{HE}$; Free School Meals (FSM) as a general indicator of low household income. Despite the centrality of parental circumstances to this area of practice, in my work as a WP practitioner located within a university team I became aware that parents are often unaware of the fact that their children are on a WP programme and unclear what the aims and criteria are. I often attend parents' evenings in local schools and colleges and while explaining to a child's grandfather what the programme was and how being a part of it would support his granddaughter but also how the targeting criteria might enable her to access scholarships and bursaries he became very distressed, saying that universities thought that he was 'thick and that they lived in a slum'. I had not previously been confronted with the direct impact of these criteria on those they seek to target and this heightened awareness of their association with deficit motivated me to investigate this issue further over the course of the MA.

A review of the academic literature indicated that the perspectives of parents and carers from the most socially disadvantaged/eligible/hard to reach groups were largely missing. The assumed lack of aspiration amongst these groups was also a source of concern. I was particularly interested in the work of Burke (BERA, 2014) who states:

Aspirations are formed through social relations, identity formations and are negotiated and renegotiated within the social contexts in which the child is situated; they are not linear in formation but cyclical and reflexive... Utilitarian and instrumental approaches to WP are stuck at the attitudinal level, unable to capture the complexity of educational aspiration.

Recent research conducted for the Department for Education (DfE, 2014) surveyed circa 400 schools and colleges and found that a lack of encouragement from parents was perceived as a challenge by more than a quarter of staff. While some staff are perhaps constructing parents from a deficit perspective it is nevertheless clear that working with families - rather than focussing interventions solely on their children - might be beneficial. An additional concern is that seeking to involve young people without considering the perspectives of parents and carers might actually be counter-productive.

For the dissertation I designed a small-scale study that would allow me to further explore these identified gaps and contradictions. Having access to the email addresses of parents and carers provided ready access to participants who would be characterised as hard to reach.' 
All twelve participants met all three of the following commonly used criteria for intervention: POLAR 3 Quintiles 1 and $2^{6}$; no family history of HE; eligible for Free school Meals ${ }^{7}$. They elected to meet me in family groups (highlighting my awareness of the importance of these inter-generational connections but also their diversity) and in settings other than at school. Four took part in face-to-face interviews and the remaining eight were interviewed as part of a focus group during a WP trip that I had arranged. It was difficult at times to separate my role as a practitioner from that of my role as a researcher but I tried to maintain boundaries for the interview process by noting any comments, questions or misunderstandings about the programme and returning to address these after the interview.

I also interviewed three teachers at schools targeted by the programme and compared their responses to those of the parents and carers. I was fortunate in that they were located in the same schools. One parent recounted an incident at her child's sixth form options evening. The family had asked whether a particular A Level or BTEC course would lead to university and they reported being told 'not to worry about university at this stage'. They said that they had then overhead another family asking the same question and being given a full answer about which universities, courses and careers the course would lead to. When asked why they had not queried this or returned to demand a similar answer, the parent stated that they did not want their child to be marked as a 'trouble-maker'. The member of staff who was interviewed at this school considered that 'some families won't leave the neighbourhood let alone go to university'. This suggested that young people are sometimes positioned by schools as being likely to follow the same trajectory as their parents and carers and therefore not always actively included in interventions. This highlights the danger of overreliance on the perspectives of staff while also echoing the concern raised by Harrison and Waller (2017) that interventions are less likely to be targeted at those least likely to go to university even though this would make a more appropriate benchmark for assessing 'success'.

The research confirmed my view that there was confusion about the programme amongst parents and carers. Some parents felt that their children had been 'seconded' to the university as they had been chosen for the programme and were therefore obliged to attend that university whereas others thought their children had been chosen because they were 'gifted and talented' and because their high academic potential had been 'spotted' by a university even if overlooked or ignored by the school. Many parents were confused by jargon and the use of euphemisms such as 'we work with children from a broad range of

\footnotetext{
${ }_{7}^{6}$ An area based indicator based on proportion progressing to university in the locality

${ }^{7}$ An income based indicator, linked to benefit entitlement and poverty.
} 
backgrounds' not realising this referred to eligibility criteria. It was also apparent that this was partly due to the way that schools communicated the aims of the programme, choosing to 'sell' it without referring explicitly to the criteria because of their association with deficit or stigma. It became clear from this confusion that if we wish to have an open and honest conversation with parents about their children making a life-changing decision, there needs to be much greater clarity around the rationale for and aims of such programmes and that the criteria need to be stated in a way that does not cause offence but is nevertheless transparent.

These findings have been used to great effect within my professional context as they have prompted the team to invest in developing stronger relationships based on improved communication with parents and carers. All summer schools now have built in parent visits. Literature has been developed that clearly explains why children have been invited to visit the university. Interventions are prefaced with parental engagement sessions and family taster days have been developed and delivered. Post-16 parent seminars have also been offered and well received. A programme to employ parent ambassadors to work in communities to share information about how they support their children at university is also in development. As a result of the skills gained from undertaking the MA, I have also been able to contribute to the development of research projects within my own institution and to studies being conducted at a national level. The insights from these parents and carers came directly out of the intersection between research and practice and these then fed into more informed interventions.

\section{Penny: Deconstructing 'worth'}

The research I pursued over the course of the MA grew out of my awareness as a careers adviser of a potential conflict of interest between a national policy agenda to increase $\mathrm{HE}$ participation, with its accompanying emphasis on WP, and the impartiality which is a core principle of the careers guidance profession. At the time I was working in two separate settings, a school and a $6^{\text {th }}$ form college. Much of my work revolved around HE progression, including acting as each institution's 'link' for WP outreach programmes. Having enthusiastically embraced the WP agenda I developed a keen sense of responsibility for providing informed, impartial guidance when young people asked me whether university is 'worth it'. This question usually concerned graduate employment prospects in relation to particular subjects or institutions. It was partly prompted by gloomy media headlines and hearsay but also reflected the WP discourse which promotes HE participation as a route to social mobility, framing the cost as a personal investment leading to enhanced earning power and life fulfilment (BIS, 2013). A growing body of academic literature lends weight to the young people's concerns, revealing outcomes which vary widely and can be affected by 
university attended and subject studied (Davies et al, 2013; de Vries, 2014; Purcell et al, 2014). Mode of participation also affects outcomes, with students 'commuting' from home appearing to be disadvantaged both in terms of overall university experience and in the graduate jobs market (Holdsworth, 2006; Callender and Jackson, 2008; Artess et al, 2014). Unfortunately, those who meet WP criteria are disproportionately represented within the universities and subjects that appear to yield the smaller financial dividends and also amongst 'commuter' students. These issues prompted the focus of the research conducted for the MA. Throughout I was mindful of the complexity of the concept of 'worth' and also of differing views as to the fundamental purpose of university, robustly debated against the backdrop of the current emphasis on financial benefit to the individual (McMahon, 2009; Faulkner, 2011; Walton, 2011; Collini, 2012; McGettigan, 2013).

The research was small-scale and involved several stages. It began with individual interviews that explored prospective undergraduates' motivation for going to university followed by a questionnaire-based study exploring recent graduates' views on their own university experience and what they drew from it. All those surveyed were former students at my school, with my position as their former careers and higher education adviser giving me direct access to a field of participants who had all had a similar preparation for university in terms of school experience and with whom I already enjoyed a measure of rapport. I was aware my position as an insider researcher could potentially discourage individuals with negative views from responding and tried to mitigate this by emphasising my openness to a range of views. Six of the questionnaire respondents volunteered to be interviewed for the final MA dissertation, affording an opportunity to explore in greater depth the issues that had so far emerged. The perspectives of university staff from three differing institutions were gathered by a further round of interviews, drawing on some of the themes arising in those with recent graduates. The focus was on better understanding what enables young people to make the most of university. The aim was to be transformative in directly considering the implications for both pre-entry preparation and post-entry support for today's diverse student body.

The most striking findings revolved around concepts of belonging and identity and the development of independence balanced against recognition of the continuing if different role of parents. This revealed the graduate interviewees' interpretations of 'worth' to be far more complex and multi-dimensional than anything measurable simply by graduate earnings. ${ }^{8}$ The

\footnotetext{
${ }^{8}$ It should be noted that the graduates interviewed for this research had all paid tuition fees of approximately $£ 3000$ a year, whilst the university staff interviewed are now working in a context where students are paying three times that amount. As the first cohort paying the higher fees had not yet graduated at the time the data
} 
importance of engaging as fully as possible with university life and using the experience to develop a sense of independent identity came across repeatedly:

To get the most out of it you do have to, not completely disregard your friends and family but you do need to learn to step away from them and just have those couple of years where you think 'I'm going to learn more about me, and what I can do.' (Interviewee 1).

The graduates who volunteered to be interviewed had all moved away to university, which limited my scope for exploring the perspectives of those who live at home. However, in the light of the views expressed, I discussed the question of catering for the specific needs of 'commuter' students with university staff, who pointed out the challenges of doing so when those students are not readily identifiable. Yet a sense of belonging enhances students' levels of engagement (and vice versa), which in turn affects graduate outcomes and assessments of 'worth'. Universities are well aware of this and many run imaginative programmes designed to ease transition and foster a sense of belonging (Morgan, 2012; Vinson et al, 2010; Thomas and Hanson, 2014), even if these do not specifically address the experience of commuter students.

Although the graduates interviewed articulated the advantages of stepping away from family, emotional, and sometimes practical, support and advice from parents were still perceived to have been crucial to their perseverance and success. One believed strongly that his parents' background helped them to support him effectively (his mother had been to university herself).

I don't think I could have done it if they hadn't had the background and the knowledge they had, , and I think had they taken a different kind of approach to me then I would've maybe dropped out, if they were like 'Come home, come home'. (Interviewee 2)

Thomas and Quinn (2007) note that parents can be ill-equipped for this role, finding parents who have not been to university more likely to encourage off-spring to come home, assuming difficulties to be outside the norm. The university staff interviewed indicated little attention has traditionally been given to supporting parents beyond open days, which inevitably highlight positive messages rather than challenges.

The quality of relationships with academics also emerged as important to students' wellbeing and academic 'success' although these have perhaps been undermined by some of the structures designed to facilitate access (such as part-time, modular courses) and the

were gathered it was too soon to explore whether higher fees have changed attitudes, although early evidence indicates this is likely to be the case (Kandiko and Mawer, 2013) 
expansion in student numbers. It came as no surprise that interviewees also found that extra-curricular activities helped foster a sense of belonging and the existing literature highlights the contribution of extra-curricular involvement to graduate employability as well (Greenbank and Hepworth, 2008; Yorke and Longden, 2008; Stuart et al, 2012). Several interviewees' extra-curricular involvement at university began with the continuation of an activity they had been involved with at school. The familiarity of the activity gave them the confidence to try it in the new setting, which in turn sometimes paved the way for trying something new. This reinforced the value of building habits of extra-curricular involvement in school or college but it also provides a reminder of the enduring inequality associated with the variability of opportunities in such settings.

The research grew directly from my work as a practitioner. The questions and concerns raised by students in the course of my work, set against the policy context within which I was working, prompted my research interest and shaped my research questions. Being a practitioner also gave me access to data, as I was able to draw on existing relationships to recruit survey respondents and interviewees. My activities as a researcher in turn directly influenced my own subsequent practice, as the findings informed the guidance I gave to young people considering university. I increasingly addressed the question of 'worth' in terms of steps which contribute to making the experience worthwhile, emphasising the importance of engaging as fully as possible once there, and highlighting the importance of making an extra effort to do so if living at home. I was able to suggest specific factors that can contribute to a sense of belonging, such as extra-curricular involvement, encouraging students to build those behaviours whilst still at school/college. I also advised considering the strength of staff/student relationships when visiting universities, as an important but often overlooked factor to bear in mind when making choices.

Sharing these findings amongst those providing guidance to young people is more problematic, as no obvious forum for such dissemination exists. There is little tradition of evidence-based, research-led careers practice within schools, although professional careers qualifications include career theory underpinned by ongoing research amongst academics. Within the state sector at least, many schools and colleges do not employ a careers adviser, and those that do exist are not always professionally trained for the role or linked to the relevant professional body (the Career Development Institute), limiting its reach as a conduit for information and research. Where a professional training has been completed, it may not be understood by teachers and senior leaders who belong to a different professional discipline. I have recently moved to a new role, within an organisation which takes CPD and research seriously, both to meet the needs of an evaluation agenda and also to continually improve its provision. This has highlighted for me the potential value of developing such 
practices across the careers guidance spectrum and the need to examine ways of facilitating this.

\section{Final reflections}

This section draws across the three accounts to highlight the potential of practitioner research in WP to be a complementary tool for positive change in a context where evaluation conducted by practitioners is the dominant model. In doing so it gives a measure of visibility and voice to this group of professionals while also perhaps, contributing to a narrowing of the gap between research and practice. It is perhaps not that surprising that the preceding accounts identify benefits from the practitioner-researcher experience consistent with those identified for other professional groups. Like Francis et al. (2017) we do not seek to reify one approach above another, however, but to suggest that in the case of WP there is considerable potential for fruitful crossover between research approaches and that this potential is both under-recognised and under-tapped.

It might be argued that WP practitioners in England are de facto practitioner researchers given their centrality to the national evaluation agenda. However, the agenda is underpinned by particular understandings of research and there are also important questions to be asked about their positioning within this agenda and the understandings of research and practice that they bring. Ruth and Fay were located in university WP teams at the time of the MA but Penny was a trained careers advisor working in a sixth form with a remit that also included WP. That all three have subsequently progressed to new roles adds weight to the idea that practitioners working around this agenda are considerably more diverse in their professional locations, roles and prior experiences than the 'umbrella' term 'widening participation practitioner' suggests. The current lack of professional development opportunities within HE suggests a failure to keep pace with the evolution and expansion of the sector. It is also indicative of a wider 'disciplinary gap' that sits in marked contrast to the wealth of academic literature about WP and which identifies this as a highly complex area of professional practice.

Challenged to strengthen the evidence base for practice the sector has become increasingly self-supporting in finding ways to meet what it identifies to be the key professional development needs. Unsurprisingly these are shaped to a large extent by an agenda set by policy makers and regulators. While there are important questions to be asked about the indicators of 'disadvantage' that are used for evaluation purposes (Gorard, 2012; Harrison and McCaig, 2015; Lynch et al, 2015; Dockery, 2016), Fay, in having the freedom to set her own research agenda was able to address this not as a technical question but as a relational 
one. In the process she gained an improved understanding of the risk of miscommunication and how this might be mitigated. Fay's efforts to identify suitable research participants also raised awareness of how few of the young people targeted for intervention met all of the 'disadvantage' indicators, suggesting that more needed to be done to reach those most likely to benefit, a point subsequently made by Harrison and Waller (2017). The insights that were generated are highly pertinent to evaluation practices but are not necessarily raised by them.

A capacity to engage with the complexity of research and practice from a position of ethical scepticism is evidenced across all three accounts. Ruth's use of the MA to explore assumptions around what confidence is and how it is developed, confirm the point made by Gorard and Smith (2006) that there is a risk of drawing unwarranted conclusions and that these might also mask potential harm. Penny's work on the 'worth' of HE came out of an explicitly ethical motivation: a sense that there was a potential conflict of interest between her role in providing impartial advice while also contributing to an agenda that emphasises $\mathrm{HE}$ as a desirable end goal in the face of increasing uncertainty, cost and risk. The conclusion that 'worth' is dependent on a multiplicity of individual, institutional and structural factors produced new insights into the kinds of advice and support that could be offered. Both examples highlight a cycle in which the taken for granted is unpicked generating the knowledge and confidence needed to reconfigure practice. In all three cases the proximity of the practitioner researcher to first-hand experiences added not only nuance or 'granularity' but also a level of visibility and voice that mitigated the concern that WP is sometimes 'done to' or 'done for' rather than 'done with'.

The relationship between research, policy and practice is complex (Gorard, 2002; Hammersley, 2005; Wilkins and Burke, 2015) and these three accounts highlight the intersections as fluid and multidirectional rather than linear and hierarchical. In holding both identities, research and practice can be seen to be continuously in play. In giving the agenda to the practitioner-researcher the questions formulated were automatically contextually relevant and they therefore fed quite readily into the kinds of situated discussions that prompted change. Dissemination via stakeholder networks has added additional transformative potential given the potential for transferable insights to emerge. How these insights and experiences might have fed in to the forms of change that the evaluation agenda seeks to measure is another question but it is clear that there are potentially valuable connections.

\section{References}


Artess, J, Mcculloch, A and P. Mok. 2014. Learning from Futuretrack: studying and living at Home available from:

https://www.gov.uk/government/uploads/system/uploads/attachment_data/file/287699/bis 14-642-learning-from-futuretrack-studying-and-living-at-home-bis-research-paper-167.pdf (accessed 12.3.14)

BIS, 2013. The Benefits of Higher Education

Participation for Individuals and Society: key findings and reports "The Quadrants". London: Department for Business, Innovation and Skills.

BIS 2014. National strategy for access and student success in higher education, London: Department for Business, Innovation \& Skills

Burke, P.J. 2013. The right to higher education: neoliberalism, gender and professional mis/recognitions. International Studies in Sociology of Education 23. 2. pp.107-126. DOI: 10.1080/09620214.2013.790660.

Burke, P.J. 2014. Access to and Widening Participation in Higher Education. BERA blog post: https://berarespectingchildren.wordpress.com/2014/07/03/access-to-andwidening-participation-in-higher-education/

Cabinet Office. 2012. University Challenge : How Higher Education Can Advance Social Mobility. A progress report by the Independent Reviewer on Social Mobility and Child Poverty, London: Cabinet Office

Callender, C and J. Jackson. 2008. Does the fear of debt constrain choice of university and subject of study? Studies in Higher Education. 33. 4. pp. 405-429. DOI:

10.1080/03075070802211802

Carr, W. 2007. Educational research as a practical science. International Journal of Research \& Method in Education. 30. 3. pp.271-286. DOI: 10.1080/17437270701614774

Church, E and M. Kerrigan. 2011. "[Aimhigher] makes you realise what you can actually accomplish." A longitudinal study of Aimhigher Nottingham City and Nottinghamshire learners. Aimhigher Nottinghamshire.

Collini, S. 2012. What are Universities For? London: Penguin 
Davies, P, Mangan, J, Hughes, A and K. Slack. 2013. Labour Market motivation and undergraduates' choice of degree subject. British Educational Research Journal. 39.

2. pp. 361-382. DOI: 10.1080/01411926.2011.646239

Dent, P., Garton, L., Hooley, T., Leonard, C., Marriot, J. and N. Moore. 2012. Higher Education Outreach to Widen Participation. Toolkits for practitioners. Resources and Glossary. HEFCE

Department for Education (DfE) School and College-level Strategies to Raise Aspirations of High-achieving Disadvantaged Pupils to Pursue Higher Education Investigation. Research report January 2014

De Vries, R (2014) Earning by Degrees. Sutton Trust, available from http://www.suttontrust.com/wp-content/uploads/2014/12/Earnings-by-Degrees-REPORT.pdf (accessed 26. 5.15)

Dockery, A., Seymour R. and P. Koshy. 2016. Promoting low socio-economic participation in higher education: a comparison of area-based and individual measures. Studies in Higher Education. 41. 9. pp.1692-1714. DOI:10.1080/03075079.20151020777

Faulkner, N. 2011. What is a University Education For? in Bailey, M and D. Freedman (Eds) The Assault on Universities: A Manifesto for Resistance. London: Pluto Press

Francis, B. Archer, L. Hodgen, J. Pepper, D Taylor, B and M-C Travers. 2017. Exploring the Relative Lack of Impact of Research on "Ability Grouping" in England: A Discourse Analytic Account. Cambridge Journal of Education. 47.1 pp.1-17.

DOI:10.1080/0305764X.2015.1093095

Gewirtz, S. Shapiro, J. Maguire, M. Mahony, P and A. Cribb. 2009. Doing teacher research: a qualitative analysis of purposes, processes and experiences. Educational Action Research. 17.4. pp.567-583. DOI: 10.1080/096507903309433.

Gorard, S. 2002. Political Control. A Way Forward for Educational research? British Journal of Education Studies. 50.3. pp.378-389. DOI: 10.1111/1467-8527.t01-1-00209 
Gorard, S. and E. Smith. 2006. Beyond the 'learning society': what have we learnt from widening participation research? International Journal of Lifelong Education. 25.6. pp.575594. DOI: $10.1080 / 02601370600989269$

Gorard, S. 2012. Who is eligible for free school meals? Characterising free school meals as a measure of disadvantage in England. British Educational Research Journal. 38. 6. pp.1003-1017. DOI: 10.1080/01411926.2011.608118

Greenbank, P and S. Hepworth. 2008. Improving the career decision-making behaviour of working class students. Journal of European Industrial Training. 32. 7. pp.492-509. DOI:10.1108/0309059081899801

Hammersley, M. 2005. The Myth of Research-based Practice: The Critical Case of Educational Inquiry. International Journal of Social Research Methodology. 8.4. pp.317-330. DOI: $10.1080 / 1364557042000232844$

Hammersley, M. 2008. Paradigm wars revived? On the diagnosis of resistance to randomized control trials and systematic review in education. International Journal of Research and Methods in Education. 31.1. pp.3-10. DOI: 01.0180/1743270801919826

Hardwick and Worsley, 2011, The Invisibility of Practitioner Research, Practice, 23. 3. pp.135-146. DOI:10.1080/09503153.2011.569971

Harridge, S. Stokoe, S. and J. Tan. 2014. That's Another Story: An Alternative to the 'Official' Way the Urban School Story is Told. Urban Review. 46. pp.904-918. DOI: 10.1007/s11256014-0310-9.

Harris, M., (2010), What more can be done to widen access to highly selective universities? OFFA

Harrison, N., and C. McCaig. 2015. An ecological fallacy in higher education policy: the use and misuse of 'low participation neighbourhoods'. Journal of Further and Higher Education. 36 .6. pp. 793-817. DOI: 10.1080/0309877X.2013.858681

Harrison, N. and R. Waller. 2017. Success and Impact in Widening Participation Policy: What Works and How Do We Know? Higher Education Policy. 30. pp.141-160. DOI: $10.1057 / \mathrm{s} 41307-016-0020-x$ 
Holdsworth, C. 2006. 'Don't you think you're missing out, living at home?' Student experiences and residential transitions. The Sociological Review. 54. 3. pp. 495-519.

Kandiko, C B and M. Mawer. 2013. Student Expectations and Perceptions of Higher Education. London: King's Learning Institute, available from:

http://www.kcl.ac.uk/study/learningteaching/kli/research/student-experience/QAAReport.pdf (accessed 10.4.15)

Kettley 2007 The past, present and future of widening participation research. British Journal of Sociology of Education. 28. 3. pp.333-347. DOI: 10.1080/01425690701252531

Khakee, A. 2003. The Emerging Gap between Evaluation Research and Practice. Evaluation. 9.3. pp.340-352

Killingsworth-Roberts, S. Crawford, P. and R. Hickman. 2010. Teacher Research as a Robust and Reflective Path to Professional Development. Journal of Early Childhood Teacher Education. 31.3.pp.258-275.DOI: 10.1080/10901027.2010.500557

Lynch. J. Walker-, B. S. Herbert .2015. Moving beyond a 'bums-on-seats' analysis of progress towards widening participation: reflections on the context, design and evaluation of an Australian government-funded mentoring programme. Journal of Higher Education Policy and Management. 37:2, 144-158, DOI:10.1080/1360080X.2015.1019122

McGettigan, A. 2013. The Great University Gamble: Money, Markets and the Future of Higher Education. London: Pluto Press

McMahon, W. 2009. Higher Learning, Greater Good: The Private and Social Benefits of Higher Education. Baltimore: The John Hopkins University Press

Morgan, M. 2012. Improving the Student Experience, A practical guide for universities and colleges, Abingdon: Routledge

OFFA . 2013. How to produce an access agreement for 2014-15. Office for Fair Access.

Purcell, K Elias, P, Atfield, G, Behle, H, Ellison, R and D. Luchinskaya. 2014. Transitions into employment, further study and other outcomes, Futuretrack Stage 4 Final Report, available from: 
http://www.hecsu.ac.uk/assets/assets/documents/Futuretrack_Stage_4_Final_report_6th_N v_2012.pdf (accessed 6.4.15)

Shaw, I. 2007. Practitioner Research: Evidence or Critique. British Journal of Social Work. 35. pp.1231-1248. DOI: 10.1093/bjsw/bch223

Strand, S. (2007). Minority Ethnic Pupils in the Longitudinal Study of Young People in England (LSYPE). DCSF

Stuart, M, Lido, C and J. Morgan. 2012. Choosing a Student Lifestyle? Questions of Taste, Cultural Capital and Gaining a Graduate Job. in Hinton-Smith, T. (Ed), Widening Participation in Higher Education: Casting the Net Wide? Hampshire: Palgrave Macmillan

Thomas, B, G and J. Hanson. 2014. Developing social integration to enhance student retention and success in higher education: the GROW@BU initiative. Widening Participation and Lifelong Learning, 16. 3. pp. 58-70.

Thomas, L and J. Quinn. 2007. First Generation Entry into Higher Education. Maidenhead: Society for Research into Higher Education and Open University Press/McGraw-Hill Education

UCAS End of Cycle Report 2016, UCAS Analysis and Research, December 2016. UCAS.

Universities UK, 2016. Working in partnership: enabling social mobility in higher education. The final report of the Social Mobility Advisory Group. http://www.universitiesuk.ac.uk/policy-and-analysis/reports/Documents/2016/working-inpartnership-final.pdf

Vetter, A. 2012, Teachers as Architects of Transformation: The Change Process of an Elementary-School Teacher in a Practitioner Research Group. Teacher Education Quarterly. 39. 1. pp.27-49.

Vinson, D, Nixon, S, Walsh, B, Walker, C, Mitchell, E and E. Zaitseva. 2010. Investigating the relationship between student engagement and transition. Active Learning in Higher Education. 11. 2. pp.131-143.

Walton, J. K. 2011. The Idea of the University in Bailey, M. and D. Freedman (Eds) The 
Assault on Universities: A Manifesto for Resistance. London: Pluto Press.

Whitchurch, C. and G. Gordon. 2010. Diversifying Academic and Professional Identities in Higher Education, Tertiary Education and Management. 16.2. pp.129-144. DOI:

$10.1080 / 13583881003757029$

Yorke, M. and Longden, B. 2008. The first-year experience of higher education in the UK, Final Report, The Higher Education Academy, available from

https://www.heacademy.ac.uk/sites/default/files/FYEFinalReport_0.pdf (accessed 29.3.15)

Zeichner, K. 2003. Teacher Research as Professional Development for P-12 Educators in the USA. Educational Action Research. 11.2. pp. 301-326.

DOI:10.1080/09650790300200211 